\title{
A CONSCIÊNCIA FONOLÓGICA E O DESEMPENHO NA ESCRITA SOB DITADO DE CRIANÇAS COM DESVIO FONOLÓGICO APÓS REALIZAÇÃO DE TERAPIA FONOAUDIOLÓGICA
}

\section{Phonological awareness and performance on writing under dictation of children with phonological disorders after speech therapy}

\author{
Helena Bolli Mota ${ }^{(1)}$, Maria das Graças de Campos Melo Filha ${ }^{(2)}$, Sabrina Schützenhorfer Lasch ${ }^{(3)}$
}

\begin{abstract}
RESUMO
Objetivo: verificar a correlação entre as habilidades de consciência fonológica e escrita sob ditado de sujeitos que apresentaram desvio fonológico após receberem alta do tratamento fonoterápico. Métodos: esses sujeitos foram avaliados após obterem alta do Serviço de Atendimento Fonoaudiológico da Universidade Federal de Santa Maria. Para avaliar a consciência fonológica foi aplicado o Instrumento de Avaliação Seqüencial - CONFIAS. A escrita foi avaliada a partir da realização da escrita sob ditado de palavras proposto no Exame de Avaliação da Linguagem -TIPITI. Resultados: de acordo com a análise estatística "r de Pearson" foram observadas as correlações: de média para forte entre escrita sob ditado e consciência de sílaba, escrita sob ditado e consciência fonológica total, sílaba e consciência fonológica total e fonema e consciência fonológica total. A única correlação significativa observada foi entre fonema e consciência fonológica total. Conclusão: salienta-se, então, a importância de estimular as habilidades em consciência fonológica, não somente em crianças na fase pré-escolar, mas principalmente em crianças com desvio fonológico, pois estas crianças são consideradas de risco para a presença de futuras dificuldades no desenvolvimento da linguagem.
\end{abstract}

DESCRITORES: Fonoterapia; Linguagem Infantil; Linguagem; Desenvolvimento da Linguagem

\section{INTRODUÇÃO}

O nível fonológico é o primeiro nível de organização da linguagem, nível dos sons ou fonemas em palavras. É o nível que corresponde à programação, escolha dos sons que entram na constituição das palavras e sua seqüência correta. Esta organização pode ser alterada durante o desenvolvimento normal da fala, mas se esta alteração persistir além do período normal de aquisição, que pode ser fixado

(1) Fonoaudióloga; Professora Associada do Curso de Fonoaudiologia e do Mestrado em Distúrbios da Comunicação Humana da Universidade Federal de Santa Maria; Doutora em Lingüística Aplicada pela Pontifícia Universidade Católica do Rio Grande do Sul.

(2) Fonoaudióloga; Mestranda em Distúrbios da Comunicação Humana pela Universidade Federal de Santa Maria.

(3) Fonoaudióloga; Fonoaudióloga da Policlínica Sarandi RS; Mestranda em Distúrbios da Comunicação Humana pela Universidade Federal de Santa Maria. em torno dos cinco anos, pode ser considerada patológica ${ }^{1}$.

Existem crianças que apresentam desvios na produção dos sons decorrentes de patologias orgânicas detectáveis, mas também existem aquelas crianças que demonstram alterações no seu desenvolvimento fonológico sem apresentar causa aparente. Estes casos são classificados como desvios fonológicos, pois decorrem de problemas organizacionais envolvendo o sistema fonológico ${ }^{2}$.

A consciência fonológica tem influência significativa no aprendizado da leitura e nas habilidades de fala. Sua instrução direta traz benefícios para crianças com desenvolvimento normal e também para aquelas consideradas de risco para a presença de dificuldades no desenvolvimento da leitura ${ }^{3}$.

Crianças em idade pré-escolar que apresentam déficits na linguagem oral podem apresentar dificuldades no desenvolvimento da leitura. É importante que estas crianças sejam identificadas e inseridas 
em programas de desenvolvimento da consciência fonológica para que estas dificuldades sejam minimizadas ${ }^{4}$.

O desenvolvimento da consciência fonológica é uma característica do período de alfabetização e implica, não só, na tomada de consciência de fonemas, mas no desenvolvimento das habilidades de trabalhar com estes fonemas ${ }^{5}$.

Em um estudo de acompanhamento de crianças com desvios fonológicos mostraram que estas crianças apresentaram melhoras significativas com a idade, entretanto, mesmo durante a adolescência e idade adulta, esses indivíduos têm performances mais baixas do que grupos controle em várias tarefas de fala, leitura, soletração e de consciência de fonemas ${ }^{6}$.

Diante da relação entre a oralidade, consciência fonológica e posterior desenvolvimento da linguagem, evidenciadas pela literatura, justifica-se o desenvolvimento deste trabalho que tem como objetivo verificar a correlação entre as habilidades de consciência fonológica e escrita de sujeitos que apresentaram desvio fonológico após receberem alta do tratamento fonoterápico.

\section{MÉTODOS}

Esta pesquisa foi desenvolvida no Serviço de Atendimento Fonoaudiológico (SAF), no Centro de Estudos de Linguagem e Fala (CELF) da Universidade Federal de Santa Maria (UFSM). Este estudo faz parte do projeto de pesquisa intitulado: "A relação entre o desvio fonológico e o desenvolvimento da linguagem".

O grupo que participou da pesquisa foi constituído por nove sujeitos, sendo quatro meninos e cinco meninas, com idades entre dez a 14 anos que cursavam entre a $4^{\underline{a}}$ e $8^{\text {a }}$ séries do ensino fundamental, no ano de 2006. Estes participantes realizaram terapia fonoaudiológica no SAF, no período de 1998 a 2002 e deixaram o serviço após receber alta. Quatro sujeitos foram tratados pelo Modelo de Ciclos Modificado, três pelo Modelo ABAB-Retirada e Provas Múltiplas e dois pelo Modelo de Oposições Máximas. O tempo médio de terapia realizada foi de vinte sessões para cada sujeito.

Os responsáveis pelos participantes da pesquisa assinaram o termo de consentimento livre e esclarecido. Os sujeitos foram localizados a partir de seus endereços e telefones registrados no arquivo do CELF, assim, foram convidados a participar da pesquisa.

Os critérios de inclusão para compor o grupo foram ter apresentado diagnóstico de desvio fonológico no período em que ingressaram no SAF, ter sido submetido à fonoterapia e recebido alta do serviço fonoaudiológico.

Foram realizadas as avaliações da consciência fonológica e da escrita sob ditado. A avaliação da consciência fonológica foi feita utilizando o Instrumento de Avaliação Seqüencial CONFIAS ${ }^{7}$. Este instrumento é constituído por um conjunto de nove tarefas (nível de sílaba) e um conjunto de sete tarefas (nível do fonema). As tarefas de nível de sílaba são as seguintes: 1) síntese silábica (S1), 2) segmentação silábica (S2), 3) identificação de sílaba inicial $(S 3), 4)$ identificação de rima $(S 4), 5)$ produção de palavra com a sílaba dada (S5), 6) identificação de sílaba medial (S6), 7) produção de rima $(S 7), 8)$ exclusão silábica (S8), 9) transposição silábica (S9). As tarefas de nível do fonema são: 1) produção de palavra que inicia com o som dado (F1), 2) identificação de fonema inicial (F2), 3) identificação de fonema final (F3), 4) exclusão fonêmica $(F 4), 5)$ síntese fonêmica (F5), 6) segmentação fonêmica (F6), 7) transposição fonêmica (F7). Cada resposta correta da criança equivale a um ponto, sendo setenta o número total de acertos possíveis (tarefas silábicas $=40$ pontos e tarefas fonêmicas = 30 pontos).

Para o cálculo das médias do teste CONFIAS foi utilizado o total de pontos das tarefas silábicas, o total de pontos das tarefas fonêmicas e o desempenho total de cada sujeito no teste (tarefas silábicas + tarefas fonêmicas). Após foi feita a média do desempenho do grupo somando-se os desempenhos individuais em cada uma das tarefas e o desempenho total de cada sujeito e dividindo-se pelo número de sujeitos.

A avaliação da escrita foi realizada a partir da aplicação da prova de escrita sob ditado do Exame de Linguagem TIPITI ${ }^{8}$. A utilização deste teste justifica-se por apresentar o material necessário para a avaliação, de acordo com cada série escolar, já que os sujeitos que participaram do estudo cursavam entre a quarta e oitava séries do ensino fundamental e também porque este exame possibilitou avaliar a linguagem adequadamente, conforme os objetivos deste estudo.

O ditado direcionado para a $4^{\mathrm{a}}, 5^{\mathrm{a}}$ e $6^{\mathrm{a}}$ séries é constituído por 35 palavras e o ditado direcionado para a $7^{\underline{a}}$ e $8^{\mathrm{a}}$ séries é composto por 36 palavras. As palavras foram ditadas, uma de cada vez, tendo-se o cuidado em realizar a pronúncia correta de cada fonema. Cada palavra correta foi considerada equivalente a um ponto. Logo, o sujeito que acertasse todas as palavras realizaria um total de $100 \%$ de acertos, ou seja, 36 palavras ou 35 palavras, de acordo com a série em questão.

A média do desempenho na escrita de palavras foi calculada somando-se o número de palavras cor- 
retas, considerando o total de palavras como cem por cento. As porcentagens de cada criança foram somadas e divididas pelo número total de sujeitos.

As avaliações foram realizadas individualmente, em ambiente silencioso, em uma sessão de 45 minutos.

Este estudo foi aprovado pelo Comitê de Ética em Pesquisa da UFSM, sob número do processo: 23081.007151/2006-35.

Para o estudo dos dados foi aplicada a análise de correlação "r de Pearson", a partir da qual foi realizada a correlação entre o ditado e as tarefas de consciência fonológica e o nível de confiança considerado foi de $5 \%$.

\section{RESULTADOS}

$\mathrm{Na}$ Tabela 1 é apresentado o desempenho dos sujeitos nas tarefas silábicas. Evidencia-se o número de acertos de cada sujeito do grupo $(\mathrm{N}=9)$ nas atividades silábicas e a média de acertos do grupo $(35,77)$.

A Tabela 2 mostra o desempenho dos sujeitos nas tarefas fonêmicas e a soma dos desempenhos nas tarefas silábicas e fonêmicas. São apresentados o número de acertos de cada sujeito do grupo $(\mathrm{N}=9)$ nas atividades fonêmicas, a média de acertos do grupo nas atividades fonêmicas $(24,22)$ e a média de acertos do grupo nas atividades fonêmicas e atividades silábicas (60).

$\mathrm{Na}$ Tabela 3 é apresentada a porcentagem de acertos de cada sujeito e a média $(57,34)$ de acertos do grupo $(\mathrm{N}=9)$ na tarefa de ditado.

A Tabela 4 mostra os resultados referentes às médias e desvio-padrão das provas. São apresentadas as médias do grupo $(\mathrm{N}=9)$ correspondentes às variáveis: ditado (57.34565), consciência de sílaba (35.77778), consciência de fonema (24.22222) e total da prova de consciência fonológica (60.00000).

Tabela 1 - Desempenho dos sujeitos nas tarefas silábicas

\begin{tabular}{lccccccccccc}
\hline Sujeitos & Série & TS1 & TS2 & TS3 & TS4 & TS5 & TS6 & TS7 & TS8 & TS9 & Total \\
\hline S1 & $5^{\text {a }}$ & 4 & 4 & 3 & 4 & 4 & 4 & 2 & 6 & 3 & 34 \\
S2 & $5^{\text {a }}$ & 4 & 4 & 4 & 3 & 4 & 4 & 2 & 7 & 4 & 36 \\
S3 & $6^{\text {a }}$ & 4 & 4 & 4 & 3 & 4 & 4 & 2 & 6 & 4 & 35 \\
S4 & $5^{\text {a }}$ & 4 & 4 & 3 & 1 & 4 & 4 & 3 & 7 & 4 & 34 \\
S5 & $5^{\text {a }}$ & 4 & 4 & 4 & 0 & 4 & 3 & 3 & 8 & 4 & 34 \\
S6 & $7^{\text {a }}$ & 4 & 4 & 4 & 4 & 4 & 4 & 4 & 8 & 4 & 40 \\
S7 & $4^{\text {a }}$ & 4 & 4 & 4 & 4 & 4 & 4 & 0 & 7 & 4 & 35 \\
S8 & $8^{\text {a }}$ & 4 & 4 & 3 & 4 & 4 & 4 & 1 & 8 & 4 & 36 \\
S9 & $5^{\text {a }}$ & 4 & 4 & 4 & 4 & 4 & 4 & 3 & 7 & 4 & 38 \\
\hline Média & - & & & & & & & & & & \\
\hline
\end{tabular}

S - sujeito; TS - tarefa silábica

Tabela 2 - Desempenho dos sujeitos nas tarefas fonêmicas e soma dos desempenhos nas tarefas silábicas e fonêmicas

\begin{tabular}{|c|c|c|c|c|c|c|c|c|c|}
\hline Sujeitos & TF1 & TF2 & TF3 & TF4 & TF5 & TF6 & TF7 & Total Fonema & $\Sigma$ Silaba/Fonema \\
\hline S1 & 4 & 4 & 3 & 5 & 3 & 2 & 3 & 24 & 58 \\
\hline S2 & 4 & 4 & 4 & 3 & 2 & 4 & 4 & 25 & 61 \\
\hline S3 & 3 & 4 & 4 & 6 & 4 & 0 & 4 & 25 & 60 \\
\hline S4 & 4 & 4 & 1 & 5 & 3 & 1 & 1 & 19 & 53 \\
\hline S5 & 4 & 4 & 4 & 6 & 4 & 4 & 3 & 29 & 63 \\
\hline S6 & 4 & 4 & 4 & 6 & 4 & 3 & 4 & 29 & 69 \\
\hline S7 & 4 & 3 & 2 & 4 & 4 & 1 & 4 & 22 & 57 \\
\hline S8 & 4 & 4 & 2 & 6 & 4 & 3 & 3 & 26 & 62 \\
\hline S9 & 4 & 4 & 4 & 3 & 2 & 1 & 1 & 19 & 57 \\
\hline Média & - & - & - & - & - & - & - & 24.22 & - \\
\hline $\begin{array}{l}\text { Média grupo } \\
\text { Silaba/Fonema }\end{array}$ & - & - & - & - & - & - & - & & 60 \\
\hline
\end{tabular}

S - sujeitos; TF - tarefa fonêmica; $\Sigma$ Silaba/Fonema - somatório das tarefas fonêmicas e tarefas silábicas. 
Tabela 3 - Desempenho por sujeito e média de acertos no ditado

\begin{tabular}{lccccccccccc}
\hline Sujeitos & $\mathbf{S 1}$ & $\mathbf{S 2}$ & $\mathbf{S 3}$ & $\mathbf{S 4}$ & $\mathbf{S 5}$ & $\mathbf{S 6}$ & $\mathbf{S 7}$ & $\mathbf{S 8}$ & $\mathbf{S 9}$ & Total & Média \\
$\%$ acertos & 57,14 & 51,43 & 68,57 & 45,71 & 60 & 86,11 & 25,71 & 50 & 71,43 & 516,11 & 57,34 \\
\hline
\end{tabular}

Tabela 4 - Resultado das médias e desvio-padrão das provas

\begin{tabular}{llccccc}
\hline Variáveis & N & Média & Desvio Padrão & Soma & Mínimo & Máximo \\
\hline Ditado & 9 & 57.34565 & 17.26154 & 516.11085 & 25.71428 & 86.11110 \\
Sílaba & 9 & 35.77778 & 2.04803 & 322.00000 & 34.00000 & 40.00000 \\
Fonema & 9 & 24.22222 & 3.70060 & 218.00000 & 19.00000 & 29.00000 \\
Total & 9 & 60.00000 & 4.55522 & 540.00000 & 53.00000 & 69.00000 \\
\hline
\end{tabular}

$\mathrm{N}$ - número de sujeitos

Tabela 5 - Resultado da correlação entre as provas

\begin{tabular}{lcccc}
\hline & Ditado & Sílaba & Fonema & Total \\
\hline Ditado & 1.00000 & 0.64350 & 0.38887 & 0.60523 \\
& - & 0.0615 & 0.3010 & 0.0842 \\
Sílaba & 0.64350 & 1.00000 & 0.18875 & 0.60294 \\
& 0.0615 & - & 0.6267 & 0.0857 \\
Fonema & 0.38887 & 0.18875 & 1.00000 & 0.89725 \\
& 0.3010 & 0.6267 & - & 0.0010 \\
Total & 0.60523 & 0.60294 & 0.89725 & 1.00000 \\
& 0.0842 & 0.0857 & 0.0010 & - \\
\hline
\end{tabular}

Pearson Correlation Coefficients, $\mathrm{N}=9$ (N: número de sujeitos). Prob > |r| under HO: Rho=0

$\mathrm{Na}$ Tabela 5 são apresentados os resultados do grupo $(\mathrm{N}=9)$ referentes à correlação entre as provas. O teste estatístico "r de Pearson" revelou algumas correlações classificadas de média para forte, ou seja, apresentam o valor de $r$ maior ou igual a 0,5 e quanto maior este valor, mais forte será a correlação. As correlações classificadas de média para forte são as seguintes: ditado de palavras isoladas e tarefas silábicas, tarefas silábicas e o total das tarefas de consciência fonológica, ditado de palavras isoladas e o total das tarefas de consciência fonológica e tarefas fonêmicas e o total das tarefas de consciência fonológica. A única correlação observada como significativa $(p<0,05)$ ocorreu entre as tarefas fonêmicas e o total das tarefas de consciência fonológica ( $r: 0,8972$ e p: 0,001).

\section{DISCUSSÃO}

Após a análise dos resultados comparando as habilidades de CF e o desempenho no ditado, foram observadas correlações de média para forte entre ditado e consciência silábica, consciência silábica e consciência fonológica total, ditado e consciência fonológica total e fonema e consciência fonológica total. Este resultado corrobora o estudo que explorou a relação entre as habilidades de CF, consciência sintática, consciência da palavra e o domínio ortográfico de crianças de $1^{\underline{a}}$ a $4^{\underline{a}}$ série do ensino fundamental, no qual foi verificada a existência dessa relação e também que as habilidades metalingüísticas e a ortografia, das crianças em estudo evoluíram em função do avanço na escolarização ${ }^{9}$. Os resultados do estudo que investigou a eficácia da intervenção em consciência fonológica de crianças com alteração de fala e de linguagem, salientaram que a intervenção em consciência fonológica pode produzir melhora na produção da fala e no desenvolvimento da leitura ${ }^{10}$. A influência da consciência fonológica, lexical e sintática sobre a aquisição da linguagem escrita foi analisada em estudo com crianças que cursavam a primeira série do ensino fundamental. Foram observadas correlações significativas entre os níveis iniciais de consciência fonológica e sintática e o desempenho final em leitura e escrita. A consciência lexical apresentou correlação somente com o resultado final em leitura ${ }^{11}$.

A correlação entre consciência de fonema e consciência fonológica total, mostrou-se significativa $(p<0,05)$ evidenciando que sujeitos que 
apresentaram desempenho ruim em atividades de tarefas fonêmicas, também apresentaram mau desempenho no total do teste de CF. Esses resultados concordam com estudo que investigou a relação entre as habilidades de consciência fonológica e sintática e o desempenho na leitura e escrita de palavras isoladas de crianças que cursavam a $3^{\underline{a}} e$ $4^{a}$ séries do ensino fundamental no qual foi observado que as dificuldades em leitura e escrita estão relacionadas com problemas de natureza fonológica e que as crianças com problemas de leitura e escrita devem realizar atividades que envolvam a consciência fonológica, não somente de percepção, mas também, atividades de manipulação intencional dos fonemas ${ }^{12}$.

A partir dos resultados deste trabalho pôde-se confirmar a relação entre a linguagem oral e o posterior desenvolvimento das habilidades lingüísticas, pois, de maneira geral, crianças que apresentam desvio fonológico, apresentarão um desempenho deficiente em habilidades que envolvam consciência fonológica. Futuramente essas dificuldades poderão influenciar, de maneira negativa, a aquisição e o desenvolvimento da escrita. Enfocando a área de leitura e escrita, foi realizado um estudo para identificar as habilidades capazes de predizer a aquisição subseqüente da linguagem escrita. De acordo com os resultados, foram identificadas como boas preditoras as habilidades de aritmética, memória fonológica, vocabulário, consciência fonológica e seqüenciamento. Os resultados deste estudo corroboraram a hipótese do déficit fonológico como causa dos problemas de leitura e escrita ${ }^{13}$. Em um estudo realizado com o objetivo de observar a relação entre a fala e a escrita de crianças com desvios fonológicos foi verificado que essas crianças apresentaram uma relativa previsibilidade quanto à repercussão do desvio fonológico na escrita ${ }^{14}$. Outro estudo relacionou a aquisição da linguagem oral com o desenvolvimento da escrita. De acordo com os seus resultados, as crianças que apresentaram aquisição fonológica incompleta aos seis anos, demonstraram tendência a uma continuidade de dificuldades no desenvolvimento da escrita quando comparadas a crianças com aquisição fonológica completa ${ }^{15}$. De acordo com as autoras do estudo no qual foi implementado um programa de intervenção de consciência fonológica em pré-escolares, crianças que apresentam dificuldades na fala, geralmente, apresentam déficit nas habilidades de consciência fonológica. Para elas, é necessário que estes déficits sejam detectados e tratados precocemente ${ }^{16}$. É importante estimular as habilidades em consciência fonológica principalmente em crianças com desvio fonológico, pois estas são consideradas de risco para a presença de futuras dificuldades no desenvolvimento da linguagem.

\section{CONCLUSÃO}

Com base nos resultados desta pesquisa, verifica-se que existe relação entre as habilidades de consciência fonológica e a escrita. Pode-se constatar que crianças com desvios fonológicos poderão apresentar dificuldades relacionadas à escrita e essa relação persiste mesmo quando se trata de crianças que foram submetidas à fonoterapia.

Salienta-se a importância da atuação fonoaudiológica no diagnóstico e intervenção precoce nos distúrbios da fala, muito comuns em crianças em idade pré-escolar e que, posteriormente, poderão interferir na aquisição e desenvolvimento do código escrito.

\begin{abstract}
Purpose: to check the relationship between phonological awareness and writing of patients with diagnostic of phonological disorders after treatment conclusion. Methods: these patients were evaluated after treatment conclusion at Speech Therapy Service of Federal University of Santa Maria. For evaluating phonological awareness we applied an assessment method referred to as called "Sequential Evaluation Instrument - CONFIAS". Writing was evaluated after dictation of some words proposed by Language Evaluation Exam - TIPITI. Results: the following correlations were detected in parallel of statistical analyze "r of Pearson": medium from strong between writing under dictation and syllable awareness, writing under dictation and total phonological awareness, syllable and total phonological awareness and phoneme and total phonological awareness. The only significant correlation was between phoneme and total phonological awareness. Conclusion: it is very important consequently to stimulate the abilities in phonological awareness, not only for children at elementary school but mainly in children with phonological disorders. These children are considered under risk for presence of future impairments in language development.
\end{abstract}

KEYWORDS: Speech Therapy; Child Language; Language; Language Development 


\section{REFERÊNCIAS}

1. Chevrie-Muller C. Semiologia dos distúrbios da linguagem na criança. In: Chevrie-Muller $\mathrm{C}$, Narbona J. A linguagem da criança: aspectos normais e patológicos. 2. ed. São Paulo: Artmed; 2005. p. 251-7.

2. Yavas MS, organizador. Desvios fonológicos em crianças: teoria, pesquisa e tratamento. Porto Alegre: Mercado Aberto; 1990. p. 256.

3. Anthony JL, Francis DJ. Development of phonological awareness. Curr Direct Psychol Sci. 2005; 14(5):255-9.

4. Nathan L, Stackhouse J, Goulandris N, Snowling MJ. The development of early literacy skills among children with speech difficulties: a test of the "critical age hypothesis". J Speech Lang Hear Res. 2004; 47(2):377-91.

5. Etchepareborda MC, Habib M. Bases neurobiológicas de la conciencia fonológica. Rev Neurol Clin. 2001; 2(1):5-23.

6. Mota HB. Terapia fonoaudiológica para os desvios fonológicos. Rio de Janeiro: Revinter; 2001. $109 \mathrm{p}$.

7. Moojen S, Lamprecht R, Santos RM, Freitas GM, Brodacz R, Siqueira M et al. Consciência fonológica: instrumento de avaliação seqüencial. São Paulo: Casa do Psicólogo; 2003.

8. Braz HA, Pellicciotti THF. Exame de linguagem TIPITI. São Paulo: MJN; 1981.
9. Queiroga BA, Borba DM, Vogeley AC. Habilidades metalingüísticas e a apropriação do sistema ortográfico. Rev Soc Bras Fonoaudiol. 2004; 9(2):73-80.

10. Gillon GT. The efficacy of phonological awareness intervention for children with spoken language impairment. Lang Speech Hear Serv Schools. 2000; 31:126-41.

11. Maluf MR, Barrera SD. Consciência metalingüística e alfabetização: um estudo com crianças da primeira série do ensino fundamental. Psicol Reflex Crít. 2003; 16(3):491-502.

12. Guimarães SR. Dificuldades no desenvolvimento da lectoescrita: o papel das habilidades metalingüísticas. Psicol Teor Pesq. 2002; 18(3):247-59.

13. Capovilla AG, Gütschow CR, Capovilla FC. Habilidades cognitivas que predizem competência de leitura e escrita. Psicol Teor Prática. 2004; 6(2):13-26.

14. Santos M, Navas A. Distúrbios de leitura e escrita: teoria e prática. São Paulo: Manole; 2002. $389 \mathrm{p}$.

15. França PM, Wolff CL, Moojen S, Rotta NT. Aquisição da linguagem oral: relação e risco para a linguagem escrita. Arq Neuro-Psiquiatr. 2004; 62(2-B):469-72.

16. Laing SP, Espeland W. Low intensity phonological awareness training in a preschool classroom for children with communication impairments. J Commun Disord. 2005; 38(1):65-82.
RECEBIDO EM: 13/06/2007

ACEITO EM: 05/12/2007

Endereço para correspondência:

Rua José Carlos Kruel, 41 / 601

Santa Maria - RS

CEP: $97060-380$

Tel: (55) 32225850

E-mail: helenabolli@ hotmail.com 